\title{
Mineralização e efeitos de biocarvão de cama de frango sobre a capacidade de troca catiônica do solo
}

\author{
Cristiano Alberto de Andrade ${ }^{(1)}$, Maria Paula Silveira Bibar ${ }^{(2)}$, Aline Reneé Coscione ${ }^{(3)}$, \\ Adriana Marlene Moreno Pires ${ }^{(1)}$ e Álvaro Guedes Soares ${ }^{(4)}$
}

\begin{abstract}
(1)Embrapa Meio Ambiente, Rodovia SP 340, Km 127,5, Caixa Postal 69, CEP 13820-000 Jaguariúna, SP, Brasil. E-mail: cristiano.andrade@embrapa.br, adriana.pires@embrapa.br (2)JBS Ambiental, Rodovia BR 040, Km 22,5, Caixa Postal 44, Zona Rural, CEP 72814-970 Luziânia, GO, Brasil. E-mail: paulabibar@yahoo.com.br ${ }^{(3)}$ Instituto Agronômico, Laboratório de Qualidade do Solo, Avenida Barão de Itapura, no 1.481, Caixa Postal 28, CEP 13012-970 Campinas, SP, Brasil. E-mail: aline@iac.sp.gov.br (4)SPPT Pesquisas Tecnológicas Ltda., Avenida Geraldo Potiguara Silveira Franco, № 950, Parque da Empresa, CEP 13803-280, Mogi Mirim, SP, Brasil. E-mail: alvaro@sppt.com.br
\end{abstract}

Resumo - O objetivo deste trabalho foi caracterizar o processo de mineralização do $\mathrm{C}$ em amostras de cama de frango e de seu respectivo biocarvão, além de determinar a capacidade de troca catiônica (CTC) e as taxas de mineralização do $C$ nos solos tratados com cama de frango e biocarvão. A mineralização do $C$ foi avaliada em experimento com quantificação do $\mathrm{C}-\mathrm{CO}_{2}$ liberado a partir de incubação (64 dias) de misturas de solo com cama de frango e de solo com biocarvão, em doses equivalentes a 0,1.000, 2.000, 4.000 e $8.000 \mathrm{mg} \mathrm{kg}^{-1} \mathrm{de}^{\mathrm{d}}$ C. Ao final da incubação, determinaram-se, nas amostras de solo, o teor de C, o pH e a CTC. A mineralização do $\mathrm{C}$ dos materiais obedeceu à cinética química de primeira ordem. Os fluxos de $\mathrm{C}_{-} \mathrm{CO}_{2}$ foram mais intensos dos 20 aos 40 dias de incubação, seguidos da redução desses fluxos até a estabilização no tempo. As taxas de mineralização do C da cama de frango e de seu biocarvão foram respectivamente de 49,7 e 5,1\%. Incrementos da CTC foram observados nos tratamentos com biocarvão, em consequência da elevação do pH, e, em ambos os materiais, em consequência de alterações do teor de $\mathrm{C}$ no solo.

Termos para indexação: biochar, carbono do solo, mineralização do carbono, pH do solo, sequestro de carbono, taxa de mineralização.

\section{Mineralization and effects of poultry litter biochar on soil cation exchange capacity}

\begin{abstract}
The objective of this work was to characterize carbon mineralization process in poultry litter samples and in its biochar, as well as to determine the soil cation exchange capacity (CEC) and the C mineralization rates in soils treated with poultry litter and biochar. Carbon mineralization was evaluated through the quantification of released $\mathrm{C}-\mathrm{CO}_{2}$ from mixtures of soil and poultry litter and of soil and biochar at doses equivalent to 0 , $1,000,2,000,4,000$, and $8,000 \mathrm{mg} \mathrm{kg}^{-1} \mathrm{C}$, in a 64-day incubation experiment. At the end of the incubation period, carbon content, $\mathrm{pH}$, and $\mathrm{CEC}$ were determined in soil samples. Carbon mineralization of the materials fitted to first order kinetics equation. Fluxes of $\mathrm{C}_{-} \mathrm{CO}_{2}$ were more intense from 20 to 40 days of incubation, followed by flux decreases until their stabilization. Carbon mineralization rates of poultry litter and its biochar were respectively 49.7 and $5.1 \%$. Increases of CEC were observed in the biochar treatments, as a consequence of $\mathrm{pH}$ rising, and in both materials due to soil-carbon content alterations.
\end{abstract}

Index terms: biochar, soil carbon, carbon mineralization, soil $\mathrm{pH}$, carbon sequestration, mineralization rate.

\section{Introdução}

O solo agrícola - entendido como compartimento global que regula fluxos de matéria e energia com a hidrosfera, atmosfera e biosfera - tem remetido à ideia de qualidade do sistema edáfico relacionada às suas funções no ambiente e a promoção da produção agrícola (Doran \& Parkin, 1994; Araújo et al., 2012). Pelo fato de a qualidade do solo não ser diretamente mensurável, utilizam-se indicadores para essa avaliação, dentre os quais destaca-se o status de carbono (C) ou de matéria orgânica edáfica no solo (Reeves, 1997; Vezzani \& Mielniczuk, 2009). Nesse sentido, sistemas produtivos vêm sendo redesenhados de forma a privilegiar aportes de $\mathrm{C}$ e minimizar perdas, estas últimas caracterizadas principalmente pela emissão de $\mathrm{CO}_{2}$, em consequência da atividade microbiana edáfica. O plantio direto - com rotação de culturas, múltiplos ciclos produtivos no ano e mobilização do solo restrita à linha de plantio/semeadura - é exemplo e síntese de 
eficiência no sequestro de C pelo solo (Corazza et al., 1999; Lovato et al., 2004; Seben Júnior et al., 2014). Outras alternativas, também fundamentais no balanço entre aportes e saídas, passam pela aplicação de fonte externa de $\mathrm{C}$ no solo, como na reciclagem agrícola de resíduos orgânicos.

A pirólise da biomassa à temperatura máxima de $700^{\circ} \mathrm{C}$ e com baixa ou zero concentração de $\mathrm{O}_{2}$ tende a incrementar a estabilidade de $\mathrm{C}$ no biocarvão produzido, em comparação à biomassa original (Lehmann et al., 2006). Assim, a aplicação do biocarvão deve representar alternativa mais efetiva para o sequestro de $\mathrm{C}$ em sistemas agrícolas. Entretanto, permanecem dúvidas acerca da influência do biocarvão sobre a dinâmica da matéria orgânica original do solo (Steinbeiss et al., 2009) e sobre a ocorrência de outros benefícios, normalmente associados à elevação do teor de $\mathrm{C}$ edáfico. Em consequência da maior estabilidade dos compostos de carbono no biocarvão, em relação aos compostos orgânicos de resíduos vegetais e do solo, decréscimos da matéria orgânica original do solo podem ser esperados (Wardle et al., 2008).

Em consequência da expansão do setor avícola no Brasil, de 1,7 para 12,3 milhões de t por ano de carne de frango, de 1987 a 2013 (União Brasileira de Avicultura, 2007, 2014), e da proibição de uso da cama de frango na alimentação animal (União Brasileira de Avicultura, 2007, 2014), um excesso desse resíduo é gerado. Entre as alternativas para destinação final da cama de frango tem-se seu uso direto no solo agrícola, como fonte de matéria orgânica e nutrientes, ou uso após compostagem para esta mesma finalidade; ou, ainda, a produção de energia e biofertilizante em biodigestores. A pirólise da cama de frango para obtenção de biocarvão representaria uma opção adicional para reciclagem desse resíduo na agricultura, principalmente visando sequestro de $\mathrm{C}$ no solo. No entanto, o sequestro de $\mathrm{C}$ no solo não deve ser a motivação exclusiva para o uso agrícola de biocarvão, pois os pagamentos por serviços ambientais e créditos de carbono não estão bem estabelecidos ou regulamentados (Cunha et al., 2013). O estabelecimento da relação entre possíveis incrementos de $\mathrm{C}$, em solos tratados com biocarvão, e benefícios outros associados a tais incrementos tornam-se fundamentais. Ao se considerar que a fração orgânica, em solos muito intemperizados, responde por 56 a 91\% da CTC (Van Raij, 1969), uma motivação interessante seria o uso de biocarvão para aumento da
CTC. Os biocarvões apresentam variação na CTC em função, principalmente, da biomassa utilizada como matéria prima (Singh et al., 2010) e da temperatura utilizada na pirólise (Song \& Guo, 2012). O efeito sobre a CTC pode ser associado à desprotonação de $\mathrm{H}^{+}$a partir da superfície de partículas minerais ou orgânicas com carga variável, em consequência do aumento do pH pela alcalinidade do biocarvão (Van Zwieten et al., 2010), embora reações de oxidação abiótica e carboxilação, na superfície das partículas do biocarvão, possam contribuir para a geração de cargas de superfície e incremento na CTC (Cheng et al., 2006).

$\mathrm{O}$ presente trabalho foi realizado partindo-se da hipótese de que a estabilidade de $\mathrm{C}$ no biocarvão da cama de frango é superior à encontrada na biomassa original, e de que os incrementos de $\mathrm{C}$, nos solos tratados com biocarvão, são acompanhados por aumentos da CTC.

O objetivo deste trabalho foi caracterizar o processo de mineralização do $\mathrm{C}$ em amostras de cama de frango e seu respectivo biocarvão, além de determinar a CTC e as taxas de mineralização do $\mathrm{C}$ nos solos tratados com cama de frango e biocarvão.

\section{Material e Métodos}

O trabalho foi desenvolvido em condições controladas, em laboratório, a partir de amostras de cama de frango e biocarvão incubadas com solo ou areia. A amostra de cama de frango - uma mistura de casca de arroz e dejeção de aves - foi obtida na região metropolitana de Campinas, SP, e seca em estufa a $38^{\circ} \mathrm{C}$ até obtenção de massa constante. Posteriormente, o material foi homogeneizado, moído e passado em peneira de malha $2 \mathrm{~mm}$.

O biocarvão foi produzido a partir da amostra seca e moída de cama de frango, por meio de pirólise lenta, em reator de laboratório tipo leito fixo (Figura 1). $\mathrm{O}$ reator (Figura 1, item 2), de formato cilíndrico, fabricado com aço inoxidável AISI 310S, apresenta um volume útil de $3 \mathrm{~L}$ e opera em regime de batelada. $\mathrm{O}$ reator foi hermeticamente fechado e posicionado no interior de uma mufla (Figura 1, item 1) com controle de temperatura. A pirólise foi realizada a $400^{\circ} \mathrm{C}$, e a taxa de aquecimento foi de $10^{\circ} \mathrm{C} \mathrm{min}^{-1}$. Através de um capilar (no 4 - Figura 1), gás nitrogênio ao fluxo de $1 \mathrm{~L} \mathrm{~min}^{-1}$ foi injetado no lado oposto à tubulação de tiragem de vapores e gases não condensáveis (nํㅜ 5 
- Figura 1). Esta corrente de gás nitrogênio tem dupla função: eliminar o ar atmosférico, inicialmente contido no reator, e prover o arraste dos vapores e gases não condensáveis gerados no processo. Posicionado no centro do reator, um tubo fechado em uma extremidade (Figura 1, item 3), permite a inserção de termopar e a mensuração da temperatura na região central do reator. Esta temperatura é a considerada como temperatura de processo. Os vapores e gases não condensáveis gerados são resfriados em condensador externo refrigerado com água (Figura 1, item 6) e o bio-óleo é coletado em um frasco (Figura 1, item 7). A corrente de gases não condensáveis (Figura 1, item 9) é passada através de borbulhador de água (Figura 1, item 8). Considerase finalizado o processo de pirólise, à temperatura de trabalho pré-definida, quando o borbulhamento se torna função exclusiva da corrente gasosa de gás nitrogênio. É possível aferir visualmente o encerramento de produção de gases não condensáveis, fechando-se momentaneamente a corrente de $\mathrm{N}$ gasoso. Durante o resfriamento, a corrente de $\mathrm{N}$ gasoso é mantida. No resfriamento do biocarvão, o material adsorve os gases no interior do reator e há a tendência de se gerar vácuo. Durante o resfriamento, o $\mathrm{N}$ gasoso impede a ocorrência deste vácuo e a consequente entrada de ar atmosférico no interior do reator, o que poderia alterar as características do biocarvão. O tempo de processamento depende da característica do reator e das condições de troca térmica. No caso do reator de laboratório (leito fixo), com diâmetro de $114 \mathrm{~mm}$ e espessura de parede de $3 \mathrm{~mm}$, nas condições de

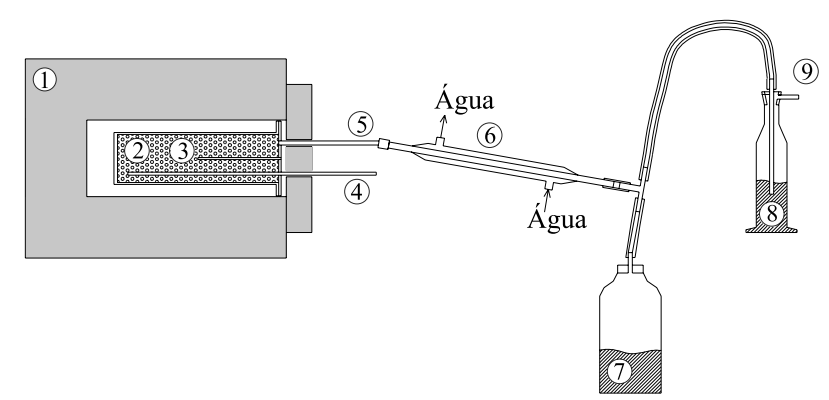

Figura 1. Representação do reator utilizado para a pirólise da amostra de cama de frango e produção de seu respectivo biocarvão: 1 , mufla $\left(1.000^{\circ} \mathrm{C}\right) ; 2$, reator de aço oxidável; 3 , tubo central para fixação de termopar tipo K; 4, entrada de gás inerte (GN2); 5, saída dos gases reagentes; 6 , condensador resfriado a água; 7 , coletor do condensado; 8 , frasco para lavagem de gases (funciona como válvula de não retorno); e 9, exaustão de gases. processo descritas, o tempo de processo situa-se entre 30 e 45 minutos. Estabeleceu-se então o tempo de 60 minutos, após ser atingida a temperatura de processo, para desligamento da mufla. O reator de pirólise de laboratório possui uma válvula de segurança montada na tubulação de injeção de $\mathrm{N}$ gasoso, não mostrada na Figura 1, para alívio de pressão do interior do reator, para o caso de entupimento do condensador.

A cama de frango e o biocarvão foram caracterizados, em triplicata, quanto ao $\mathrm{pH}$, umidade e teores de $\mathrm{C}, \mathrm{N}, \mathrm{P}$, $\mathrm{K}, \mathrm{Ca}, \mathrm{Mg}$ e $\mathrm{S}$ (Tabela 1), por meio de métodos descritos em Andrade \& Abreu (2006). A CTC dos materiais foi determinada conforme método oficial do Ministério da Agricultura, Pecuária e Abastecimento (Brasil, 2007) para fertilizantes orgânicos, que emprega lavagens com solução $\mathrm{HCl} 0,5 \mathrm{~mol} \mathrm{~L}^{-1}$, acetato de cálcio $0,5 \mathrm{~mol} \mathrm{~L}^{-1} \mathrm{e}$ posterior titulação com $\mathrm{NaOH}$. Além disso, a CTC foi também quantificada por meio de método alternativo (Glória et al., 1965), com solução de acetato de amônio a pH 7,0 e adaptações descritas em Andrade et al. (2006). O método se fundamenta no uso do $\mathrm{NH}_{4}^{+}$ como cátion-índice, fornecido via solução de acetato de amônio $\left(\mathrm{CH}_{3} \mathrm{COONH}_{4}, \mathrm{pH} 7,0\right)$ e deslocamento do $\mathrm{NH}_{4}{ }^{+}$, por meio de troca iônica com $\mathrm{Ca}^{+2}$ fornecido via solução de acetato de cálcio $\left(\mathrm{Ca}\left(\mathrm{CH}_{3} \mathrm{COO}\right)_{2}, \mathrm{pH} 7,0\right)$. $\mathrm{O} \mathrm{NH}_{4}{ }^{+}$foi determinado pelo método de destilação a vapor (Cantarella \& Trivelin, 2001).

Os experimentos com incubação, para avaliação da dinâmica de mineralização de $\mathrm{C}$ da cama de frango e

Tabela 1. Caracterização química da cama de frango e do seu respectivo biocarvão.

\begin{tabular}{|c|c|c|}
\hline Atributo & Cama de frango & Biocarvão \\
\hline$\overline{\mathrm{pH}_{\mathrm{CaCl} 2}}$ & $7,8 \pm 0,0$ & $10,2 \pm 0,1$ \\
\hline Umidade (\%) & $6,2 \pm 0,1$ & $2,8 \pm 0,0$ \\
\hline $\mathrm{C}$ total $\left(\mathrm{g} \mathrm{kg}^{-1}\right)$ & $376 \pm 1$ & $429 \pm 0$ \\
\hline $\mathrm{N}$ total $\left(\mathrm{g} \mathrm{kg}^{-1}\right)$ & $36,8 \pm 0,3$ & $31,8 \pm 0,0$ \\
\hline Relação C/N & 10 & 13 \\
\hline Fósforo $\left(\mathrm{g} \mathrm{kg}^{-1}\right)$ & $10,5 \pm 0,3$ & $29,4 \pm 0,6$ \\
\hline Potássio $\left(\mathrm{g} \mathrm{kg}^{-1}\right)$ & $26,9 \pm 0,9$ & $47,2 \pm 1,0$ \\
\hline Cálcio $\left(\mathrm{g} \mathrm{kg}^{-1}\right)$ & $21,1 \pm 0,8$ & $48,3 \pm 0,7$ \\
\hline Magnésio $\left(\mathrm{g} \mathrm{kg}^{-1}\right)$ & $3,8 \pm 0,1$ & $14,6 \pm 2,0$ \\
\hline Enxofre $\left(\mathrm{g} \mathrm{kg}^{-1}\right)$ & $6,4 \pm 0,1$ & $10,0 \pm 0,4$ \\
\hline $\mathrm{CTC}^{(1)}\left(\mathrm{mmol}_{\mathrm{c}} \mathrm{kg}^{-1}\right)$ & $555 \pm 28$ & $80 \pm 4$ \\
\hline $\mathrm{CTC}^{(2)}\left(\mathrm{mmol}_{\mathrm{c}} \mathrm{kg}^{-1}\right)$ & $521 \pm 4$ & $196 \pm 4$ \\
\hline
\end{tabular}

${ }^{(1)} \mathrm{CTC}$ potencial a $\mathrm{pH} 7,0$, conforme método indicado pelo Ministério da Agricultura, Pecuária e Abastecimento (Brasil, 2007), com uso de lavagens com $\mathrm{HCl}$ e acetato de cálcio. ${ }^{(2)} \mathrm{CTC}$ potencial a pH 7,0, conforme método adaptado de Glória et al. (1965), apresentado por Andrade et al. (2006), com uso de acetato de amônio. 
do biocarvão, foram instalados com a mistura de doses desses materiais e amostras de solo ou areia.

A amostra de solo da camada de 0 a $20 \mathrm{~cm}$ foi obtida de área com Latossolo Vermelho-Amarelo distroférrico (Santos etal., 2006), pertencente ao Instituto Agronômico (IAC), no Centro Experimental Central, em Campinas, SP. Após secagem ao ar e passagem em peneira com malha $2 \mathrm{~mm}$, três subamostras foram encaminhadas para determinações de atributos químicos quanto à fertilidade, conforme Van Raij et al. (2001), e análise granulométrica, conforme Camargo et al. (2009). O solo apresentou as seguintes características: $\mathrm{pH}$ em $\mathrm{CaCl}_{2}, 4,8 \pm 0,1$; C, $18 \pm 0 \mathrm{~g} \mathrm{~kg}^{-1}$; P extraído com resina, $2 \pm 0 \mathrm{mg} \mathrm{dm}^{-3}$; $\mathrm{K}^{+}, 2,6 \pm 0,1 \mathrm{mmol}_{\mathrm{c}} \mathrm{dm}^{-3} ; \mathrm{Ca}^{+2}, 17 \pm 1 \mathrm{mmol}_{\mathrm{c}} \mathrm{dm}^{-3}$; $\mathrm{Mg}^{+2}, 6 \pm 0 \mathrm{mmol}_{\mathrm{c}} \mathrm{dm}^{-3} ; \mathrm{H}+\mathrm{Al}$ (acidez potencial), $31 \pm 2 \mathrm{mmol}_{\mathrm{c}} \mathrm{dm}^{-3}$; saturação por bases, $45 \pm 2 \%$; e teores de argila e areia iguais a, respectivamente, $299 \mathrm{~g} \mathrm{~kg}^{-1} \mathrm{e}$ $622 \mathrm{~g} \mathrm{~kg}^{-1}$.

Utilizou-se também para incubação areia para filtro de piscina e o preparo consistiu de queima em mufla a $550^{\circ} \mathrm{C}$ e posterior lavagem com solução de $\mathrm{HCl}$ a $10 \%$ e água deionizada, de forma a garantir a eliminação de qualquer material orgânico porventura presente.

A estabilidade das fontes de $\mathrm{C}$ foi avaliada por meio de incubação, com duração de 64 dias, tendo-se utilizado $300 \mathrm{~g}$ de solo ou areia em mistura com doses dos materiais, conforme Coscione \& Andrade (2006).

As doses de $\mathrm{C}$ foram igualadas entre os materiais e corresponderam à aplicação de $0,1.000,2.000,4.000$ e $8.000 \mathrm{mg} \mathrm{kg}^{-1}$, equivalentes a $0,2,4,8,16 \mathrm{t} \mathrm{ha}^{-1}$. Utilizou-se o delineamento experimental inteiramente casualizado, com quatro repetições.

A cama de frango e o biocarvão foram aplicados secos e com granulometria inferior a $2 \mathrm{~mm}$, com a finalidade de homogeneização das misturas e de padronização do tamanho das partículas.

Além dos tratamentos com cama de frango e biocarvão, adicionou-se um tratamento com sacarose p.a. à dose de $2.000 \mathrm{mg} \mathrm{kg}^{-1}$ de $\mathrm{C}$, para servir de referência quanto à rapidez do processo de degradação dos materiais, uma vez que é substrato de $\mathrm{C}$ facilmente mineralizável pela microbiota.

A incubação foi realizada em potes de plástico herméticos $(1,5 \mathrm{~L})$, colocados em ambiente escuro e à temperatura controlada de $28 \pm 1^{\circ} \mathrm{C}$. A umidade do solo ou da areia com os respectivos tratamentos foi mantida a 70\% da capacidade de retenção de água.

$\mathrm{O}$ C- $\mathrm{CO}_{2}$ liberado foi capturado com solução padronizada de $\mathrm{NaOH} 0,5 \mathrm{~mol} \mathrm{~L}^{-1}$ colocada em frascos, no interior dos potes de 1,5 L, e trocadas diariamente nos primeiros cinco dias de incubação e a cada três ou quatro dias no restante do período de incubação. A quantificação do $\mathrm{C}-\mathrm{CO}_{2}$ que reagiu com a solução de $\mathrm{NaOH}$ foi feita por meio de leitura da condutividade elétrica (Rodella \& Saboya, 1999).

Os valores do $\mathrm{C}-\mathrm{CO}_{2}$ liberado, descontado o controle, foram acumulados no tempo, para posterior ajuste à equação de cinética química de primeira ordem $\mathrm{C}_{\text {mineralizado }}=\mathrm{C}_{0} \times\left(1-\mathrm{e}^{-\mathrm{kt}}\right)$, em que: $\mathrm{C}_{\text {mineralizado }}$ é a quantidade $\left(\mathrm{mg} \mathrm{kg}^{-1}\right)$ de $\mathrm{C}$ liberado, na forma de $\mathrm{CO}_{2}$, no tempo t; $\mathrm{C}_{0}$ é a fração $\left(\mathrm{mg} \mathrm{kg}^{-1}\right)$ potencialmente mineralizável; $\mathrm{k}$ é a constante de velocidade da reação de mineralização de $\mathrm{C}$ (por dia); e t é o tempo em dias. Ressalta-se que $\mathrm{C}_{0}$ e k são coeficientes do ajuste ao modelo de cinética química dos resultados de $\mathrm{C}-\mathrm{CO}_{2}$ liberado em função do tempo. Tais valores são válidos para a caracterização do processo de mineralização, quando o ajuste é significativo a $5 \%$ de probabilidade pelo teste t.

Ao final da incubação, o solo foi seco ao ar, peneirado em malha $2 \mathrm{~mm}$ e encaminhado para análises de CTC efetiva ( $\mathrm{pH}$ natural). $\mathrm{O}$ método utilizado para determinação da CTC efetiva foi o de Glória et al. (1965), com adaptações descritas em Andrade et al. (2006), em que o $\mathrm{K}^{+}$é utilizado como cátion-índice fornecido via solução de $\mathrm{KCl} \mathrm{1,0} \mathrm{mol} \mathrm{L}^{-1}$ e, posteriormente, deslocado por troca iônica pelo $\mathrm{Ca}^{+2}$ fornecido via solução de $\mathrm{CaCl}_{2} \quad 0,5 \mathrm{~mol} \mathrm{~L} \mathrm{~L}^{-1}$. A determinação do $\mathrm{K}^{+}$no extrato foi realizada em fotometria de emissão de chama.

A CTC potencial foi estimada por meio da determinação dos teores de $\mathrm{K}^{+}, \mathrm{Ca}^{+2}, \mathrm{Mg}^{+2}$ e $\mathrm{H}+\mathrm{Al}$, conforme Van Raij et al. (2001), com K, Ca e Mg extraídos por resina de troca iônica, e o $\mathrm{H}+\mathrm{Al}$ obtido indiretamente por meio de leitura do $\mathrm{pH}$ SMP.

Subamostras de solo foram moídas finamente, passadas em peneira com malha de $0,149 \mathrm{~mm}$, secas a $38^{\circ} \mathrm{C}$ e utilizadas para quantificação do teor total de $\mathrm{C}$, por combustão a seco em analisador elementar CN.

Os resultados foram tratados estatisticamente com análise de variância e posterior aplicação do teste de Tukey, a 5\% de probabilidade (cama de frango e biocarvão), e de regressão (doses).

\section{Resultados e Discussão}

A cama de frango estimulou a atividade microbiana edáfica, que foi evidenciada pelos fluxos de $\mathrm{C}$, na forma 
de $\mathrm{CO}_{2}\left(\mathrm{C}-\mathrm{CO}_{2}\right)$, enquanto o estímulo provocado pelo biocarvão foi menos evidente (Figura 2). É importante destacar que fluxos semelhantes de C- $\mathrm{CO}_{2}$ entre o solo tratado com biocarvão e o solo-controle, em diversas datas de avaliação, são indicativos de que não ocorreu prejuízo à atividade microbiana em função da aplicação do material pirolisado.

A liberação de $\mathrm{C}-\mathrm{CO}_{2}$ foi mais intensa nos primeiros 20-40 dias de incubação da cama de frango ou nos 20 dias iniciais, no caso dos tratamentos-controle e solo com adição de glicose ou biocarvão (Figura 2). A rápida degradação da cama de frango ou de dejetos de galinha, após aplicação no solo, em geral, é conhecida e esperada como consequência da estreita relação $\mathrm{C} / \mathrm{N}$ do material, próxima de 10:1 (Vanegas Chacón, 2006; Pitta et al., 2012). Também é fato relatado na literatura especializada que, durante os primeiros dias de incubação, compostos orgânicos mais lábeis são preferencialmente consumidos pelos microrganismos, e materiais mais recalcitrantes são acessados pela microbiota com o decorrer do tempo e a menores taxas (Giacomini et al., 2003; Andrade et al., 2006).

Observados os resultados de C- $\mathrm{CO}_{2}$ acumulado no tempo, para a dose de $2.000 \mathrm{mg} \mathrm{kg}^{-1} \mathrm{de} \mathrm{C}$ aplicada, ficou evidente que o $\mathrm{C}$ aplicado ao solo via biocarvão é mais estável do que o $\mathrm{C}$ presente nos compostos orgânicos da cama de frango (Figura 3). $\mathrm{O}$ C- $\mathrm{CO}_{2}$ acumulado no tratamento com biocarvão foi inferior a $30 \%$ do liberado nos outros dois tratamentos e a estabilização dos fluxos ocorreu em menos de 10 dias. Para sacarose e cama de frango, a estabilização dos fluxos de $\mathrm{C}-\mathrm{CO}_{2}$ ocorreu com cerca de 20 dias de incubação.

Quando a cama de frango, o biocarvão e a sacarose foram incubados com areia previamente queimada e lavada, os tratamentos com sacarose e biocarvão praticamente não exibiram liberação de $\mathrm{C}-\mathrm{CO}_{2}$, durante os primeiros 18 dias de incubação, para a dose de $2.000 \mathrm{mg} \mathrm{kg}^{-1}$ (Figura $3 \mathrm{~B}$ ). A explicação está relacionada ao preparo da areia para a incubação e a inocuidade microbiológica tanto da sacarose, quanto do biocarvão. A queima da areia a $550^{\circ} \mathrm{C}$ deve ter eliminado a comunidade microbiana previamente existente no material, bem como o processo de pirólise deve ter afetado de forma semelhante a comunidade microbiana previamente existente na cama de frango. No caso da sacarose, utilizou-se reagente p.a. e, portanto, com baixa carga microbiológica. Nos tratamentos com cama de frango, não foram verificados atrasos no processo de mineralização de $\mathrm{C}$, uma vez que o próprio material serviu de inóculo de microrganismos na incubação.

No 18을 dia de incubação aplicaram-se $2 \mathrm{~g}$ de solo (o mesmo usado no experimento) sobre a superfície das misturas com areia, com o objetivo de servir de inóculo de microrganismos, o que deu início ao processo de mineralização de $\mathrm{C}$, evidenciado pela liberação de $\mathrm{C}-\mathrm{CO}_{2}$ (Figura 3).
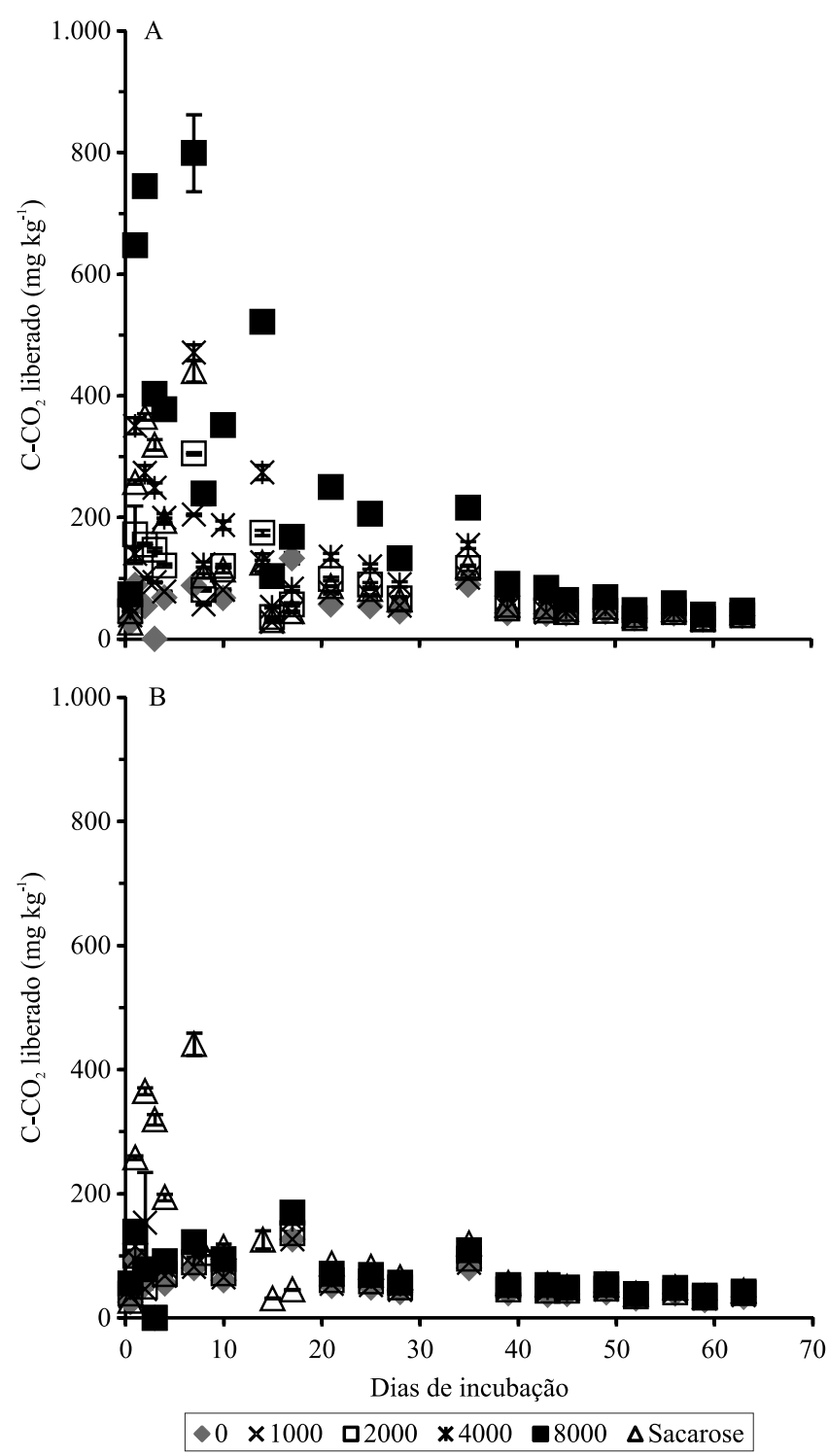

Figura 2. Valores médios acumulados de $\mathrm{C}$, como $\mathrm{CO}_{2}$ $\left(\mathrm{C}-\mathrm{CO}_{2}\right)$, em função do tempo de até 64 dias de incubação de amostras de solo, misturadas com cama de frango (A) e biocarvão (B), em doses de 0, 1.000, 2.000, 4.000 e $8.000 \mathrm{mg} \mathrm{kg}^{-1}$ de $\mathrm{C}$, além de sacarose à dose de $2.000 \mathrm{mg} \mathrm{kg}^{-1}$ de $\mathrm{C}$.

Pesq. agropec. bras., Brasília, v.50, n.5, p.407-416, maio 2015 DOI: $10.1590 / \mathrm{S} 0100-204 X 2015000500008$ 
Em geral, na mistura dos materiais com areia, os valores de $\mathrm{C}-\mathrm{CO}_{2}$ ficaram abaixo dos verificados na mistura com solo, exceto no caso da sacarose, em que o valor final acumulado foi semelhante entre as duas situações.

O compartimento potencialmente mineralizável de $\mathrm{C}$ dos materiais foi avaliado por meio dos resultados de $\mathrm{C}_{0}$, obtidos nos ajustes ao modelo de cinética química. Na menor dose aplicada, o compartimento mineralizável da cama de frango incubada com solo foi 2,4 vezes maior do que o verificado para o biocarvão, e a diferença entre as fontes de $\mathrm{C}$ aumentou com o incremento da dose (Figura $4 \mathrm{~A}$ ).

Percebe-se, portanto, que a pirólise concentrou $\mathrm{C}$ na massa final do biocarvão (Tabela 1) e alterou a qualidade dos compostos de $\mathrm{C}$ presentes, em comparação ao material original. A maior estabilidade de $\mathrm{C}$ no biocarvão é resultante de perdas variáveis de $\mathrm{H}, \mathrm{O}, \mathrm{C}$ e $\mathrm{N}$ durante a pirólise, em que se preserva relativamente mais $\mathrm{C}$ e, assim, se reduzem as relações $\mathrm{H} / \mathrm{C}, \mathrm{O} / \mathrm{C}$ e $(\mathrm{O}+\mathrm{N}) / \mathrm{C}$ (Novak et al., 2009). Essas alterações da pirólise da cama de frango correspondem ao incremento do pico principal de arilas (compostos aromáticos) e redução das alquilas, metilenos e carboidratos (celulose e hemicelulose), em que estes

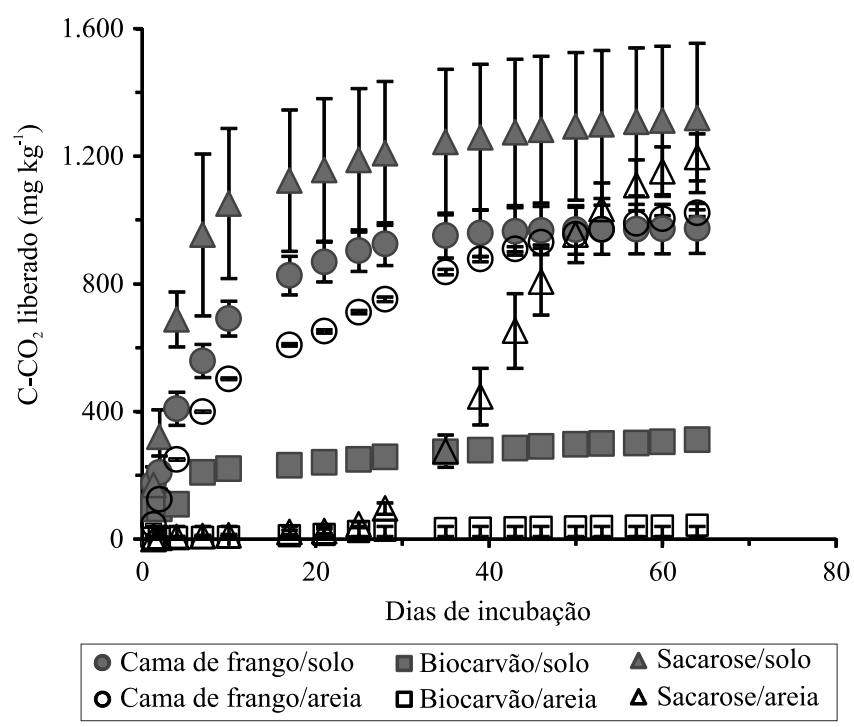

Figura 3. Valores médios acumulados de carbono, liberado como $\mathrm{CO}_{2}\left(\mathrm{C}-\mathrm{CO}_{2}\right)$, em função do tempo de incubação até 64 dias de amostras de solo ou areia com cama de frango, biocarvão e sacarose, à dose de $2.000 \mathrm{mg} \mathrm{kg}^{-1}$ de C. Barras verticais representam os valores de desvio-padrão. últimos tendem a zero a temperaturas acima de $350^{\circ} \mathrm{C}$. (Cimò et al., 2014).

As taxas de mineralização de $\mathrm{C}$ da cama de frango e do biocarvão corresponderam aos coeficientes angulares das retas apresentadas na Figura 4. $\mathrm{Na}$ mistura com solo, as taxas de mineralização de $\mathrm{C}$ da cama de frango e do biocarvão foram 49,7 e 5,1\%, respectivamente (Figura 4A). Valor semelhante de taxa de mineralização foi obtido por Sigua et al. (2014), que determinaram que $4,3 \%$ do total de $\mathrm{C}$ do biocarvão de cama de frango foi liberado como $\mathrm{CO}_{2}$, após mistura com solo a $5.110 \mathrm{mg} \mathrm{kg}^{-1} \mathrm{de} \mathrm{C}$ e incubação por 50 dias.

Os resultados de mineralização de $\mathrm{C}$ nos materiais avaliados suportam, pelo menos em parte, a afirmação
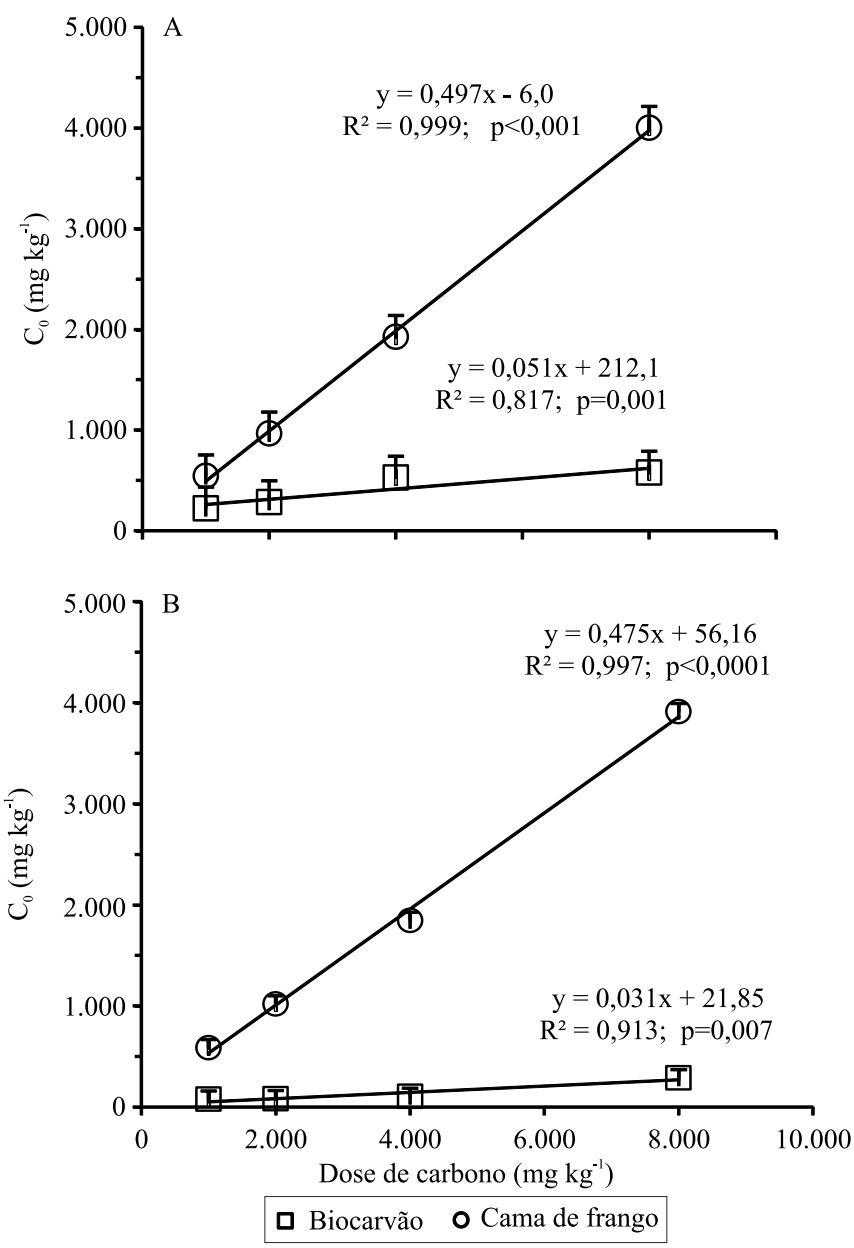

Figura 4. Carbono potencialmente mineralizável $\left(\mathrm{C}_{0}\right)$, em função de doses de carbono aplicadas via cama de frango e biocarvão, após mistura com solo (A) ou areia (B). Barras verticais representam a diferença mínima significativa, pelo teste de Tukey, a 5\% de probabilidade. 
de Lehmann et al. (2006), de que produtos pirolisados são mais eficazes para sequestrar $\mathrm{C}$ no solo e auxiliar a mitigação do efeito estufa. No entanto, é oportuno lembrar que o balanço de $\mathrm{C}$, a partir da biomassa original, deve considerar a eficiência de recuperação de $\mathrm{C}$ no biocarvão. Quanto à cama de frango, Song \& Guo (2012) definiram que a eficiência de recuperação de C no biocarvão foi de $64 \%$, em pirólise lenta a $300^{\circ} \mathrm{C}$, e que o efeito do aumento da temperatura até $600^{\circ} \mathrm{C}$ é inversamente proporcional à eficiência de recuperação de $\mathrm{C}$ no biocarvão. Considerando-se que a diferença de mineralização entre a cama de frango e o biocarvão foi de cerca de $45 \%$, e assumindo-se que a recuperação de C no biocarvão produzido a $400^{\circ} \mathrm{C}$ tenha sido igual a $52 \%$ (Song \& Guo, 2012), fica evidente que os gases e o óleo gerados na pirólise são fundamentais para uma avaliação mais completa do desempenho ambiental do biocarvão.

Com os resultados de $\mathrm{C}-\mathrm{CO}_{2}$ da incubação com areia, a taxa de mineralização de $\mathrm{C}$ do biocarvão foi $3,1 \%$, enquanto o $\mathrm{C}$ da cama de frango alcançou valor semelhante ao verificado no solo, 47,6\% (Figura 4 B).

A ocorrência de efeito "priming" - aceleração da degradação de matéria orgânica -, causada pelo biocarvão, foi observada tanto por Wardle et al. (2008), no material orgânico na interface solo-liteira, quanto por Luo et al. (2011), na matéria orgânica original. Na pesquisa de Wardle et al. (2008), conduzida por dez anos, em condição de campo na Suécia, ou seja, sob variação da distribuição de chuvas, efeitos indiretos do biocarvão sobre a manutenção da umidade na interface solo-liteira, bem como sobre a retenção de nutrientes, podem explicar o favorecimento à degradação do material vegetal, em presença do pirolisado (Bruun \& El-Zehery, 2012). Em laboratório, cujas condições de temperatura e umidade para degradação dos compostos orgânicos são controladas, o efeito "priming" pode ocorrer como consequência de compostos orgânicos solúveis no biocarvão (Luo et al., 2011). Esses compostos são responsáveis pelo estímulo à atividade microbiana, em curto período, na incubação do biocarvão com solo, o que define inclusive a taxa de mineralização de C do biocarvão (Smith et al., 2010; Cross \& Sohi, 2011; Bruun \& El-Zehery, 2012). A ocorrência ou não de efeito "priming" é associada a características quantitativas e qualitativas da matéria orgânica do próprio solo, à dose de biocarvão utilizada e à fração solúvel de C no biocarvão (Luo et al., 2011).
$\mathrm{Na}$ presente pesquisa, a menor mineralização de $\mathrm{C}$ ocorrida quando o biocarvão foi incubado com areia, pode ser atribuída ao atraso no início do processo, conforme destacado anteriormente, mas não se descarta a possibilidade de estímulo à mineralização adicional de $\mathrm{C}$ do solo pela mistura com biocarvão, $\mathrm{o}$ que configuraria o efeito "priming".

A CTC determinada no biocarvão variou com o método de determinação (Tabela 1); pelo método oficial para fertilizantes orgânicos e condicionadores de solo (Brasil, 2007), o valor de CTC situou-se em torno de $41 \%$ do valor determinado com o uso de acetato de amônio, adaptado de Glória et al. (1965) (Andrade et al., 2006). O valor de CTC de $196 \mathrm{mmol}_{\mathrm{c}} \mathrm{kg}^{-1}$ é mais próximo de outros citados na literatura para biocarvão de cama de frango, produzido entre 400 e $550{ }^{\circ} \mathrm{C}$, na faixa de 400 a $600 \mathrm{mmol}_{\mathrm{c}} \mathrm{kg}^{-1}$ (Gaskin et al., 2008; Song \& Guo, 2012; Van Zwieten et al., 2013), em que o método utilizado também é fundamentado na saturação dos sítios de troca com amônio fornecido via solução de acetato de amônio.

$\mathrm{Na}$ mistura com o solo, houve efeito linear das doses de $\mathrm{C}$ sobre a CTC efetiva dos tratamentos com biocarvão e, em média, a CTC efetiva do solo com biocarvão foi superior à proporcionada pela aplicação da cama de frango somente nas doses de $4.000 \mathrm{e}$ $8.000 \mathrm{mg} \mathrm{kg}^{-1}$ de $\mathrm{C}$ (Figura $5 \mathrm{~A}$ ). A alcalinidade do biocarvão incrementou o $\mathrm{pH}$ do solo (Figura $5 \mathrm{~B}$ ) e foi responsável, pelo menos em parte, pelo aumento da CTC efetiva, o que pode ser comprovado pela correlação significativa entre $\mathrm{pH}$ e CTC efetiva nos tratamentos com biocarvão (Figura $5 \mathrm{C}$ ).

Ao avaliar a CTC potencial, por meio da soma de cátions trocáveis e da acidez potencial a $\mathrm{pH} 7,0$, observaram-se incrementos de 3 e 4 mmol $_{c} \mathrm{dm}^{-3}$ a cada $1.000 \mathrm{~g} \mathrm{~kg}^{-1}$ de $\mathrm{C}$ aplicado via biocarvão e cama de frango, respectivamente (Figura $6 \mathrm{~A}$ ).

$\mathrm{Na}$ maior parte das doses de $\mathrm{C}$ estudadas, os valores de CTC potencial proporcionados pela cama de frango foram superiores aos verificados para o biocarvão (Figura 6A), o que mostra que a cama de frango foi mais efetiva na geração de cargas no solo. Deve-se, ainda, ressaltar que houve mineralização de cerca de $50 \%$ do $\mathrm{C}$ inicialmente aplicado ao solo como cama de frango, enquanto para o biocarvão esse valor foi somente de $5 \%$. Tal fato implica num remanescente de $\mathrm{C}$ no solo tratado com biocarvão superior ao remanescente de $\mathrm{C}$ no solo com cama, o que é confirmado pelos teores de $\mathrm{C}$ no solo ao final da incubação (Figura 6 B). A taxa 

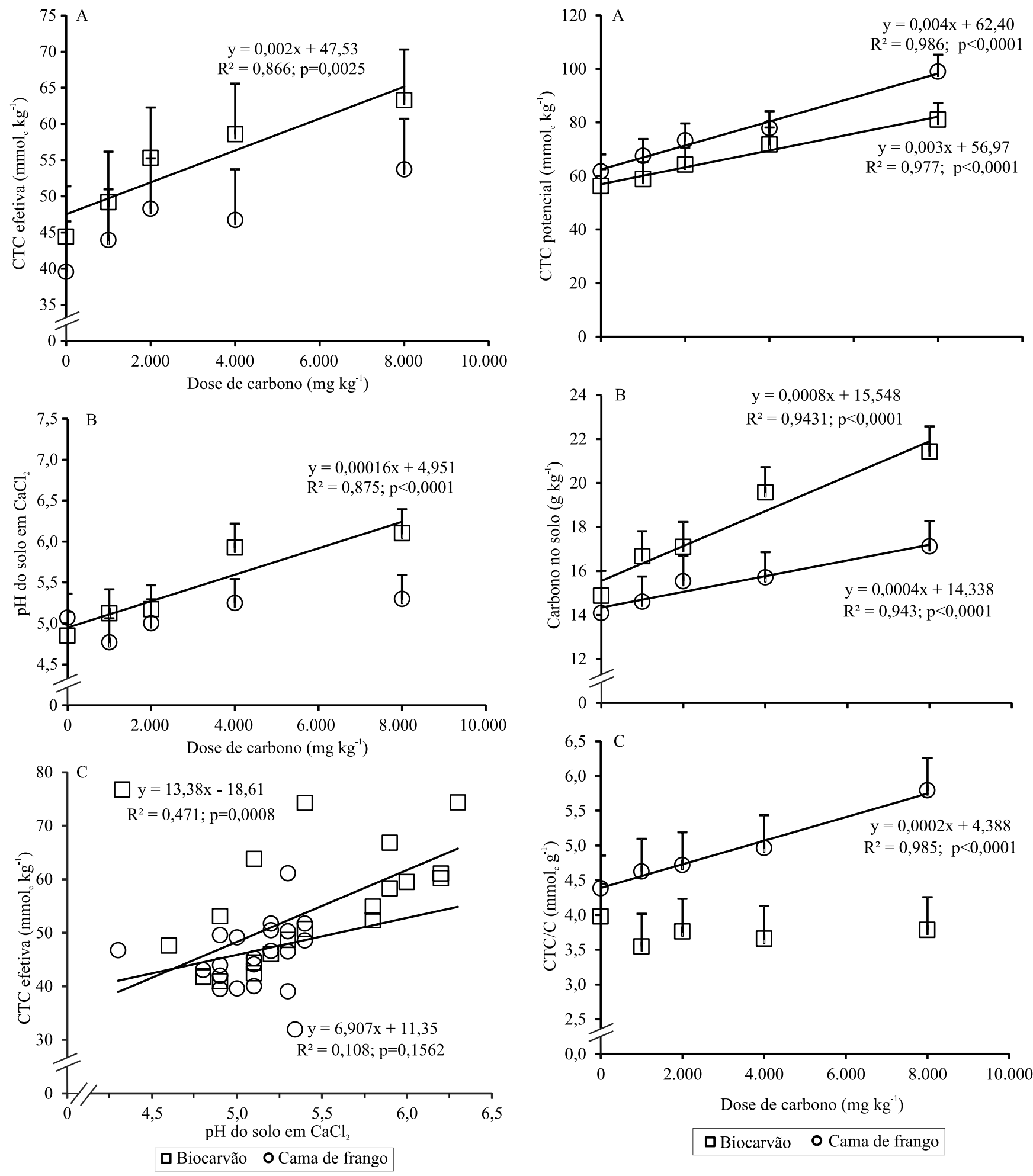

Figura 5. CTC efetiva (A), valores de $\mathrm{pH}$ do solo (B) e correlações entre estas variáveis $(\mathrm{C})$, em função da aplicação de doses de cama de frango e biocarvão. Barras verticais representam a diferença mínima significativa, pelo teste de Tukey, a $5 \%$ de probabilidade.

Figura 6. Valores de CTC potencial, a pH 7,0 (A), teores totais de carbono no solo, após incubação $(\mathrm{B})$, e relação CTC potencial/C, em amostras de solo tratadas com doses de cama de frango e biocarvão $(C)$. Barras verticais representam a diferença mínima significativa, pelo teste de Tukey, a $5 \%$ de probabilidade. 
de acúmulo de C no solo com biocarvão foi de $80 \%$ do adicionado e, para a cama de frango, esse valor foi de $40 \%$.

A relação $\mathrm{CTC} / \mathrm{C}$ evidenciou maior quantidade de cargas negativas por unidade de $\mathrm{C}$, nas misturas de solo e cama de frango, do que nas misturas de solo e biocarvão. $\mathrm{O}$ envelhecimento do biocarvão no solo e a ocorrência de reações de oxidação abiótica em sua superfície tendem a incrementar a CTC com o tempo, principalmente pela formação de grupos carboxílicos (Cheng et al., 2006), cuja magnitude dependerá também do $\mathrm{pH}$ do sistema (Lee et al., 2010). Como o C do biocarvão é recalcitrante no ambiente, incrementos adicionais na CTC devem ser esperados com o tempo, principalmente em caso de reaplicações do material numa mesma área.

\section{Conclusões}

1. A mineralização do carbono presente em compostos orgânicos na cama de frango e no seu respectivo biocarvão, após aplicação no solo, é caracterizada por período inicial com fluxos mais intensos de $\mathrm{C}-\mathrm{CO}_{2}$ e redução desses fluxos com o tempo, segundo modelo de cinética química de primeira ordem.

2. As taxas de mineralização do carbono da cama de frango $(49,7 \%)$ e do biocarvão $(5,1 \%)$ evidenciam a recalcitrância de $\mathrm{C}$ nos compostos orgânicos após a pirólise.

3. A capacidade de troca de cátions do solo é incrementada com o uso de doses de biocarvão, com ganhos em carbono; porém, a quantidade de cargas por unidade de $\mathrm{C}$ no solo com biocarvão é inferior à de cargas no solo com cama de frango.

\section{Referências}

ANDRADE, C.A.; OLIVEIRA, C. de; CERRI, C.C. Cinética de degradação da matéria orgânica de biossólidos após aplicação no solo e relação com a composição química inicial. Bragantia, v.65, p.659-668, 2006. DOI: 10.1590/S0006-87052006000400017.

ANDRADE, J.C. de; ABREU, M.F. de. Análise química de resíduos sólidos para monitoramento e estudos agroambientais. Campinas: Instituto Agronômico, 2006. 177p.

ARAÚJO, E.A. de; KER, J.C.; NEVES, J.C.L.; LANI, J.L. Qualidade do solo: conceitos, indicadores e avaliação. Revista Brasileira de Tecnologia Aplicada nas Ciências Agrárias, v.5, p.187-196, 2012.
BRASIL. Ministério da Agricultura, Pecuária e Abastecimento. Instrução Normativa SDA n ${ }^{\circ} 28$, de 27 de julho de 2007. Diário Oficial [da] República Federativa do Brasil, 31 jul. 2007.

BRUUN, S.; EL-ZEHERY, T. Biochar effect on the mineralization of soil organic matter. Pesquisa Agropecuária Brasileira, v.47, p.665-671, 2012. DOI: 10.1590/S0100-204X2012000500005.

CAMARGO, O.A. de; MONIZ, A.C.; JORGE, J.A.; VALADARES, J.M.A.S. Métodos de análise química, mineralógica e física de solos do Instituto Agronômico de Campinas. Campinas: Instituto Agronômico, 2009. 77p. (IAC. Boletim técnico, 106).

CANTARELlA, H.; TRIVELIN, P.C.O. Determinação do nitrogênio inorgânico em solo pelo método da destilação a vapor. In: VAN RAIJ, B.; ANDRADE, J.C. de; CANTARELLA, H.; QUAGGIO, J.A. (Ed.). Análise química para avaliação da fertilidade de solos tropicais. Campinas: Instituto Agronômico, 2001. p.271-276.

CHENG, C.-H.; LEHMANN, J.; THIES, J.E.; BURTON, S.D.; ENGELHARD, M.H. Oxidation of black carbon by biotic and abiotic processes. Organic Geochemistry, v.37, p.1477-1488, 2006. DOI: 10.1016/j.orggeochem.2006.06.022.

CIMÒ, G.; KUCERIK, J.; BERNS, A.E.; SCHAUMANN, G.E.; ALONZO, G.; CONTE, P. Effect of heating time and temperature on the chemical characteristics of biochar from poultry manure. Journal of Agricultural and Food Chemistry, v.62, p.1912-1918, 2014. DOI: $10.1021 /$ jf405549z.

CORAZZA, E.J.; SILVA, J.E.; RESCK, D.V.S.; GOMES, A.C. Comportamento de diferentes sistemas de manejo como fonte ou depósito de carbono em relação à vegetação de Cerrado. Revista Brasileira de Ciência do Solo, v.23, p.425-432, 1999.

COSCIONE, A.R.; ANDRADE, C.A. Protocolos para avaliação da dinâmica de resíduos orgânicos no solo. In: ANDRADE, J.C. de; ABREU, M.F. de. Análise química de resíduos sólidos para monitoramento e estudos agroambientais. Campinas: Instituto Agronômico, 2006. p.159-177.

CROSS, A.; SOHI, S.P. The priming potential of biochar products in relation to labile carbon contents and soil organic matter status. Soil Biology and Biochemistry, v.43, p.2127-2134, 2011. DOI: 10.1016/j.soilbio.2011.06.016.

CUNHA, N.R.V. da; MAMED, D. de O.; FEITOZA, F.J.R. Novas transformações da ciência, do meio ambiente e do direito: o comércio de certificados de créditos de carbono. Hiléia: Revista do Direito Ambiental da Amazônia, n.19, p.251-270, 2013.

DORAN, J.W.; PARKIN, T.B. Defining and assessing soil quality. In: DORAN, J.W.; COLEMAN, D.C.; BEZDICEK, D.F.; STEWART, B.A. (Ed.). Defining soil quality for a sustainable environment. Madison: Soil Science Society of America, 1994. p.3-21. (SSSA. Special publication, 35).

GASKIN, J.W.; STEINER, C.; HARRIS, K.; DAS, K.C.; BIBENS, B. Effect of low-temperature pyrolysis conditions on biochar for agricultural use. Transactions of the American Society of Agricultural and Biological Engineers, v.51, p.2061-2069, 2008.

GIACOMINI, S.J.; AITA, C.; HÜBNER, A.P.; LUNKES, A.; GUIDINI, E.; AMARAL, E.B. do. Liberação de fósforo e potássio durante a decomposição de resíduos culturais em plantio direto. 
Pesquisa Agropecuária Brasileira, v.38, p.1097-1104, 2003. DOI: $10.1590 / \mathrm{S} 0100-204 X 2003000900011$.

GLÓRIA, N.A.; CATANI, R.A.; MATUO, T. A determinação da capacidade de troca de cátions do solo pelo método do EDTA. Revista de Agricultura, v.40, p.193-198, 1965.

LEE, J.W.; KIDDER, M.; EVANS, B.R.; PAIK, S.; BUCHANAN III, A.C.; GARTEN, C.T.; BROWN, R.C. Characterization of biochars produced from cornstovers for soil amendment. Environmental Science and Technology, v.44, p.7970-7974, 2010. DOI: $10.1021 /$ es $101337 x$.

LEHMANN, J.; GAUNT, J.; RONDON, M. Bio-char sequestration in terrestrial ecosystems - a review. Mitigation and Adaptation Strategies for Global Change, v.11, p.395-419, 2006. DOI: 10.1007/s11027-005-9006-5.

LOVATO, T.; MIELNICZUK, J.; BAYER, C.; VEZZANI, F. Adição de carbono e nitrogênio e sua relação com os estoques no solo e com o rendimento do milho em sistemas de manejo. Revista Brasileira de Ciência do Solo, v.28, p.175-187, 2004. DOI: 10.1590/S0100-06832004000100017.

LUO, Y.; DURENKAMP, M.; DE NOBILI, M.; LIN, Q.; BROOKES, P.C. Short term soil priming effects and the mineralization of biochar following its incorporation to soils of different pH. Soil Biology and Biochemistry, v.43, p.2304-2314, 2011. DOI: 10.1016/j.soilbio.2011.07.020.

NOVAK, J.M.; LIMA, I.; XING, B.; GASKIN, J.W.; STEINER, C.; DAS, K.C.; AHMEDNA, M.; REHRAH, D.; WATTS, D.W.; BUSSCHER, W.J.; SCHOMBERG, H. Characterization of designer biochar produced at different temperatures and their effects on a loamy sand. Annals of Environmental Science, v.3, p.195-206, 2009.

PITTA, C.S.R.; ADAMI, P.F.; PELISSARI, A.; ASSMANN, T.S.; FRANCHIN, M.F.; CASSOL, L.C.; SARTOR, L.R. Year-round poultry litter decomposition and N, P, K and Ca release. Revista Brasileira de Ciência do Solo, v.36, p.1043-1053, 2012. DOI: 10.1590/S0100-06832012000300034.

REEVES, D.W. The role of soil organic matter in maintaining soil quality in continuous cropping systems. Soil and Tillage Research, v.43, p.131-167, 1997. DOI: 10.1016/S0167-1987(97)00038-X.

RODELLA, A.A.; SABOYA, L.V. Calibration for conductimetric determination of carbon dioxide. Soil Biology and Biochemistry, v.31, p.2059-2060, 1999. DOI: 10.1016/S0038-0717(99)00046-2.

SANTOS, H.G. dos; JACOMINE, P.K.T.; ANJOS, L.H.C. dos; OLIVEIRA, V.A. de; OLIVEIRA, J.B. de; COELHO, M.R.; LUMBRERAS, J.F.; CUNHA, T.J.F. (Ed.). Sistema brasileiro de classificação de solos. 2.ed. Rio de janeiro: Embrapa Solos, 2006. 306p.

SEBEN JÚNIOR, G. de F.; CORÁ, J.E.; LAL, R. Effect of cropping systems in no-till farming on the quality of a Brazilian Oxisol. Revista Brasileira de Ciência do Solo, v.38, p.1268-1280, 2014. DOI: 10.1590/S0100-06832014000400023.

SIGUA, G.C.; NOVAK, J.M.; WATTS, D.W.; CANTRELL, K.B.; SHUMAKER, P.D.; SZÖGI, A.A.; JOHNSON, M.G. Carbon mineralization in two Ultisols amended with different sources and particle sizes of pyrolyzed biochar. Chemosphere, v.103, p.313-321, 2014. DOI: 10.1016/j.chemosphere.2013.12.024.

SINGH, B.; SINGH, B.P.; COWIE, A.L. Characterisation and evaluation of biochars for their application as a soil amendment. Soil Research, v.48, p.516-525, 2010. DOI: 10.1071/SR10058.

SMITH, J.L.; COLLINS, H.P.; BAILEY, V.L. The effect of young biochar on soil respiration. Soil Biology and Biochemistry, v.42, p.2345-2347, 2010. DOI: 10.1016/j.soilbio.2010.09.013.

SONG, W.; GUO, M. Quality variations of poultry litter biochar generated at different pyrolysis temperatures. Journal of Analytical and Applied Pyrolysis, v.94, p.138-145, 2012. DOI: 10.1016/j.jaap.2011.11.018.

STEINBEISS, S.; GLEIXNER, G.; ANTONIETTI, M. Effect of biochar amendment on soil carbon balance and soil microbial activity. Soil Biology and Biochemistry, v.41, p. 1301-1310, 2009. DOI: 10.1016/j.soilbio.2009.03.016.

UNIÃO BRASILEIRA DE AVICULTURA. Relatório anual 2006/2007. São Paulo: UBA, 2007. 80p. Disponível em: <http:// www.ubabef.com.br/publicacoes $\mathrm{m}=75 \&$ date $=2007-04>$. Acesso em: 16 set. 2014.

UNIÃO BRASILEIRA DE AVICULTURA. Relatório anual 2014. São Paulo: UBA, 2014. 55p. Disponível em: $<$ http://www. ubabef.com.br/publicacoes? $\mathrm{m}=75 \&$ date $=2014-03>$. Acesso em: 16 set. 2014.

VAN RAIJ, B. A capacidade de troca de cátions das frações orgânica e mineral em solos. Bragantia, v.28, p.85-112, 1969.

VAN RAIJ, B.; ANDRADE, J.C. de; CANTARELLA, H.; QUAGGIO, J.A. (Ed.). Análise química para avaliação da fertilidade de solos tropicais. Campinas: Instituto Agronômico, 2001. 285p.

VAN ZWIETEN, L.; KIMBER, S.; MORRIS, S.; CHAN, K.Y.; DOWNIE, A.; RUST, J.; JOSEPH, S.; COWIE, A. Effects of biochar from slow pyrolysis of papermill waste on agronomic performance and soil fertility. Plant and Soil, v.327, p.235-246, 2010. DOI: $10.1007 / \mathrm{s} 11104-009-0050-\mathrm{x}$.

VAN ZWIETEN, L.; KIMBER, S.W.L.; MORRIS, S.G.; SINGH, B.P.; GRACE, P.R.; SCHEER, C.; RUST, J.; DOWNIE, A.E.; COWIE, A.L. Pyrolysing poultry litter reduces $\mathrm{N}_{2} \mathrm{O}$ and $\mathrm{CO}_{2}$ fluxes. Science of the Total Environment, v.465, p.279-287, 2013. DOI: 10.1016/j.scitotenv.2013.02.054.

VANEGAS CHACÓN, E.A. Caracterização, decomposição e biodisponibilidade de nitrogênio e fósforo de materiais orgânicos de origem animal e vegetal. 2006. 143p. Tese (Doutorado) - Universidade Federal de Viçosa, Viçosa.

VEZZANI, F.M.; MIELNICZUK, J. Uma visão sobre qualidade do solo. Revista Brasileira de Ciência do Solo, v.33, p.743-755, 2009. DOI: 10.1590/S0100-06832009000400001.

WARDLE, D.A.; NILSSON, M.-C.; ZACKRISSON, O. Fire-derived charcoal causes loss of forest humus. Science, v.320, p.629, 2008. DOI: 10.1126/science. 1154960 .

Recebido em 2 de outubro de 2014 e aprovado em $1^{\circ}$ de abril de 2015 